mdre

BUILDING KNOWLEDGE

TO IMPROVE SOCIAL POLICY

口

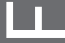

ப

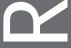

$\boldsymbol{n}$
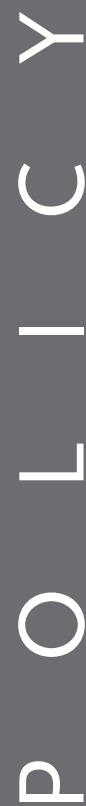

\title{
More Graduates \\ Two-Year Results from an Evaluation of Accelerated Study in Associate Programs (ASAP) for Developmental Education Students
}

\author{
By Susan Scrivener and Michael J. Weiss
}

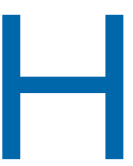

aving a college degree is increas-

ingly important in the U.S. labor market, and workers with a degree earn substantially more, on average, than those without. Recently there has been an unprecedented national focus on boosting the stubbornly low graduation rates of students in community colleges. Community colleges serve millions of the nation's undergraduates, but only about one-third of those students graduate within five years.' Graduation rates are even lower for students who enter college without the math, reading, or writing skills required for college-level courses and thus need to take developmental (remedial) courses. ${ }^{2}$ In addition, most college students take longer to graduate than is considered "normal." For example, a survey of students who started at a public two-year college found that only 4 percent graduated with an associate's degree within two years. ${ }^{3}$

Educators have tried many reforms to help improve the success rates of community college students. Most of the reforms have been short term, lasting only one or two semesters, and have addressed no more than a few barriers to student success. The Accelerated Study in Associate Programs (ASAP) is an ambitious and promising exception. Operated by the City University of New York (CUNY), which serves over half a million students annually and is the largest public university system in the country, ASAP provides a comprehensive array of services and supports over a three-year period to help more students graduate and to help them graduate sooner. The program aims to simultaneously address multiple barriers to student achievement over multiple semesters, and is one of the most aggressive efforts in the country to improve the success rates of low-income students.

This brief describes the ASAP program and the students in the study, presents the two-year effects of the program, offers some conclusions, and shares next steps for ASAP and the random assignment evaluation.

\section{B A C K G R O U N D}

CUNY launched ASAP at its six community colleges in 2007, with funding from New York City's Center for Economic Opportunity. CUNY's internal evaluation of ASAP found substantial, positive effects on students' academic progress. ${ }^{4}$ In 2009 , CUNY decided to expand the program and commission an external evaluation using a random assignment methodology, which MDRC is conducting. The box on page 2 covers some of the benefits of a random assignment design.

ASAP originally served only students who were deemed "college-ready" based on CUNY Assessment Tests in reading, writing, and math. In fall 2009, the program began to also serve students who need some developmental education, based on their CUNY Assessment Test scores. MDRC's evaluation, which began in spring 2010 , 
WHY IS RANDOM ASSIGNMENT

IMPORTANT?

The evaluation of CUNY's Accelerated Study in Associate Programs (ASAP) and many of MDRC's other studies use a random assignment research design to measure the effectiveness of policies or programs created to help students succeed. This approach - unusual in higher education research - involves a lottery-like process to place students who are eligible and willing to participate into either a program group that receives a new or enhanced service or intervention, or a control group that receives the regular college services. Random assignment ensures that the characteristics of students in both the program and control groups are not systematically different at the start of the study. By tracking both groups over time and comparing their outcomes, MDRC is able to estimate the impact, or "value added," of the program. Random assignment, a rigorous method of evaluation, produces results that policymakers and practitioners alike can readily understand and trust.

examines the impact of ASAP on low-income students who need one or two developmental courses.

The random assignment evaluation compares ASAP with "business as usual" at the participating colleges. For the evaluation, eligible students were randomly placed into either a program group, whose members were eligible for ASAP, or a control group, whose members were eligible to receive standard college services. Generally, like the services at most community colleges, the regular services at the colleges in the study are far less intensive than ASAP's services.

The first report from the evaluation, published in 2012, shared very promising early findings on students' academic outcomes: Compared with regular college courses and services, ASAP increased full-time enrollment and credits earned during students' first semester in the study. ASAP also increased the proportion of students who completed their developmental course work that semester, and increased the proportion who returned to college for a second semester.

Two years after students entered the study, ASAP has continued to substantially improve academic outcomes. Most important, the program increased the proportion of students who graduated after two years. To the authors' knowledge, ASAP's two-year effects are unparalleled in large-scale experimental evaluations of programs in higher education to date.

\section{WHAT SERVICES DOES ASAP PROVIDE?} While ASAP provides a broad range of supports, a lot is also required and expected from participating students. Below are the key components of the ASAP model - ASAP as designed. As part of the evaluation, MDRC is examining how the colleges in the study implemented the program and what students in the study experienced. After the program model is described, some preliminary findings from the implementation research are presented.

\section{Requirements and Messages}

Enroll full time. ASAP requires students to enroll full time (12 or more credits) in the fall and spring semesters.

\section{Take developmental courses early. ASAP} encourages students to take any necessary developmental courses early in their time in college.

Graduate quickly. ASAP encourages students to graduate with an associate's degree within three years.

\section{Course Enrollment}

ASAP seminar. Students are required to take a noncredit ASAP seminar that covers 
topics such as goal setting and academic planning for at least their first year in the program.

Block-scheduled classes. Groups of students organized by major take three or more courses in the same semester during their first year in ASAP. The block typically includes a developmental education course and often includes an ASAP seminar.

\section{Student Services}

Comprehensive advisement. Students are assigned to an ASAP adviser with a small caseload: 60 to 80 students. (Typical community college advisers can be responsible for 1,000 students or more.) ASAP advisers are expected to provide comprehensive academic and interpersonal support. Students are required to meet with their adviser at least twice a month. ${ }^{5}$

Tutoring. ASAP tutors provide general support both inside and outside the classroom. Some ASAP students are required to attend tutoring frequently, such as those taking developmental courses or those on academic probation.

Career services. ASAP career and employment specialists help with career planning and, if needed, job placement. Students are required to meet with the career and employment specialist once a semester.

\section{FINANCIAL SUPPORTS}

Tuition waiver. ASAP waives any gap between students' financial aid and their tuition and fees. (ASAP requires students to complete a Free Application for Federal Student Aid, known as FAFSA.)

Free MetroCards. The program provides free monthly MetroCards for use on public transportation. ${ }^{6}$ The MetroCard is tied to fulfilling certain program requirements, such as meeting with an adviser or attending tutoring.

Free textbooks. ASAP provides free textbooks for all classes. Students must return them at the end of the semester.

The program also includes periodic social events for participating students and an ASAP-wide student leadership program in which groups of students can participate in leadership-building activities. The colleges sometimes have an ASAP-dedicated social work intern from the Hunter College School of Social Work (which is part of the CUNY system), who is available to meet with students about personal issues and to provide counseling.

In order to study how ASAP was actually implemented, MDRC staff conducted field research, visiting the participating colleges periodically to interview staff and administrators. MDRC also received information about students' financial aid and ASAP tuition waiver receipt from CUNY. Students in the study - both program group and control group students - were surveyed about a year after random assignment about their experiences in college. Detailed findings from the implementation research will be shared in a later report, but an initial look follows.

Early analysis of the implementation data suggests that, overall, ASAP has been generally well implemented, with some variation across the components and across the campuses, as the model allows. Specifically:

Requirements and messages. ASAP advisers consistently communicated the requirement to attend college full time, the message to take developmental education courses early, and the importance of graduating within three years. 
Course enrollment. Most program group students took the ASAP seminar in the semesters in which it was offered. Field research suggests that the implementation of ASAP's block-scheduling component varied somewhat across the participating colleges. All three colleges offered blocks of classes for students during the first year. At two of the colleges, some students took all the classes in a specific block, but many took only part of the block. The main purpose of the blocked classes was to ensure that ASAP students took at least some of their classes with other ASAP students. At the third college, most students were required to take all the classes in a specific block during the first semester, in a coordinated learning community. ${ }^{7}$ During the second semester, the college's blocked classes resembled those of the other two colleges.

Student services. On the survey, students in the program group reported substantially more contact with an adviser during their first year in the study than did their counterparts in the control group, and they reported higher rates of satisfaction with the advising they received. They also reported substantially higher levels of participation in tutoring and career services.

Financial supports. As noted above, all students in the study were from low-income families. As a result, they were likely to get enough financial aid to fully cover their tuition and fees: only a small proportion of the program group had a gap between their tuition and fees and financial aid, and thus needed the tuition waiver. Implementation data suggest that ASAP students got a MetroCard in most of the months they were in school, and they consistently got free textbooks.

\section{WHO IS IN THE STUDY?} ASAP is offered at six of CUNY's seven community colleges, ${ }^{8}$ and the evaluation takes place at the three largest: Borough of Manhattan Community College, Kingsborough Community College in Brooklyn, and LaGuardia Community College in Queens. CUNY and MDRC selected the colleges primarily based on their willingness to participate in an evaluation and their capacity to reach the desired sample size goals.

The study focuses on low-income students those with family income below 200 percent of the federal poverty level and those eligible for a federal Pell Grant - who needed one or two developmental courses when they entered the study. (As noted above, ASAP also serves students who do not need any developmental courses; those students were not included in the study.) Incoming students are required to take the CUNY Assessment Tests, which are designed to assess basic skills proficiency in reading, writing, and math, before they take classes. During the study period, students at CUNY's community colleges were not required to take developmental courses when they started school, but they had to complete any developmental courses before they took certain courses for college-level credit, such as freshman English and college algebra, and before they could graduate or transfer to a CUNY four-year school.

To be eligible for the study, a student also had to be an entering freshman or a continuing student who had earned fewer than 12 credits, a New York City resident, and willing to enroll in college full time. Finally, students also had to be in an ASAP-eligible major — the colleges excluded a few majors with requirements that make it difficult to graduate in two or three years. ${ }^{9}$

ASAP staff invited eligible students at each of the three colleges to participate in the evalua- 
tion. Students who agreed to participate were assigned, at random, to either a program group or a control group. The colleges randomly assigned two groups (or cohorts) of students for the study — one just before the spring 2010 semester and the other just before the fall 2010 semester. (One college, LaGuardia, assigned students only before the fall 2010 semester.) MDRC is tracking the sample members' academic outcomes over time. As described in the box on page 2, differences in the two research groups' outcomes provide an estimate of the average effect, or impact, of ASAP compared with the usual college services.

A total of 896 students are in the study sample. Based on a survey that students completed just before they were randomly assigned, their average age when they entered the study was 21.5 years. About two-thirds of the sample members are women. Only a small minority of the students were married or had any children when they entered the study, and most lived with their parents. Reflecting the student body at the three colleges, the study sample is racially and ethnically diverse: just under half identified themselves as Hispanic, about 34 percent as black, 10 percent as white, and 8 percent as Asian or Pacific Islander.

As mentioned above, one of the eligibility criteria for the study was being in need of one or two developmental courses. Reflecting the eligibility criteria, the vast majority of students in the sample needed one or two developmental courses when they entered the study. ${ }^{10}$

\section{W HAT WERE ASA P'S EF F C T S ?}

\section{Previous Findings}

MDRC's first report on the effects of ASAP was based on one complete semester of follow-up for the full sample, and persistence in school through an additional semester. The report showed that during the first semester, ASAP increased the proportion of students who enrolled full time (from 85 percent to 96 percent) and increased the average number of credits students earned (from 9.3 credits to 11.4 credits). In addition, ASAP increased the proportion of students who returned to school in the second semester from 80 percent to 90 percent."

\section{New Findings}

The main findings presented in this brief track students in the research sample for two years after they entered the study. In that time, students who were offered ASAP those in the program group - clearly outperformed their control group counterparts with respect to persistence, credit accumulation, and graduation. Findings are described in detail below.

\section{ASAP Improves Rates of Persistence}

Figure 1, on page 6, displays enrollment rates at any CUNY college during the first two years after students were randomly assigned. Each year is broken into two semesters, and each semester is divided into a longer main session and a shorter intersession. (See the box on page 6 for a description of main sessions and intersessions.)

The overall pattern of persistence (for both the program and control groups) shows that students enroll at much higher rates during main sessions compared with intersessions, and that enrollment rates tend to decrease over time as some students stop out (that is, take time off) or drop out.

After the first main session, ASAP consistently increased students' likelihood of enrolling during each session. To the authors' knowledge, these effects are unparalleled in large-scale experimental evaluations of programs in higher education to date. During the main sessions 


\section{FIGURE 1: ASAP BOOSTS ENROLLMENT OVER TWO YEARS}

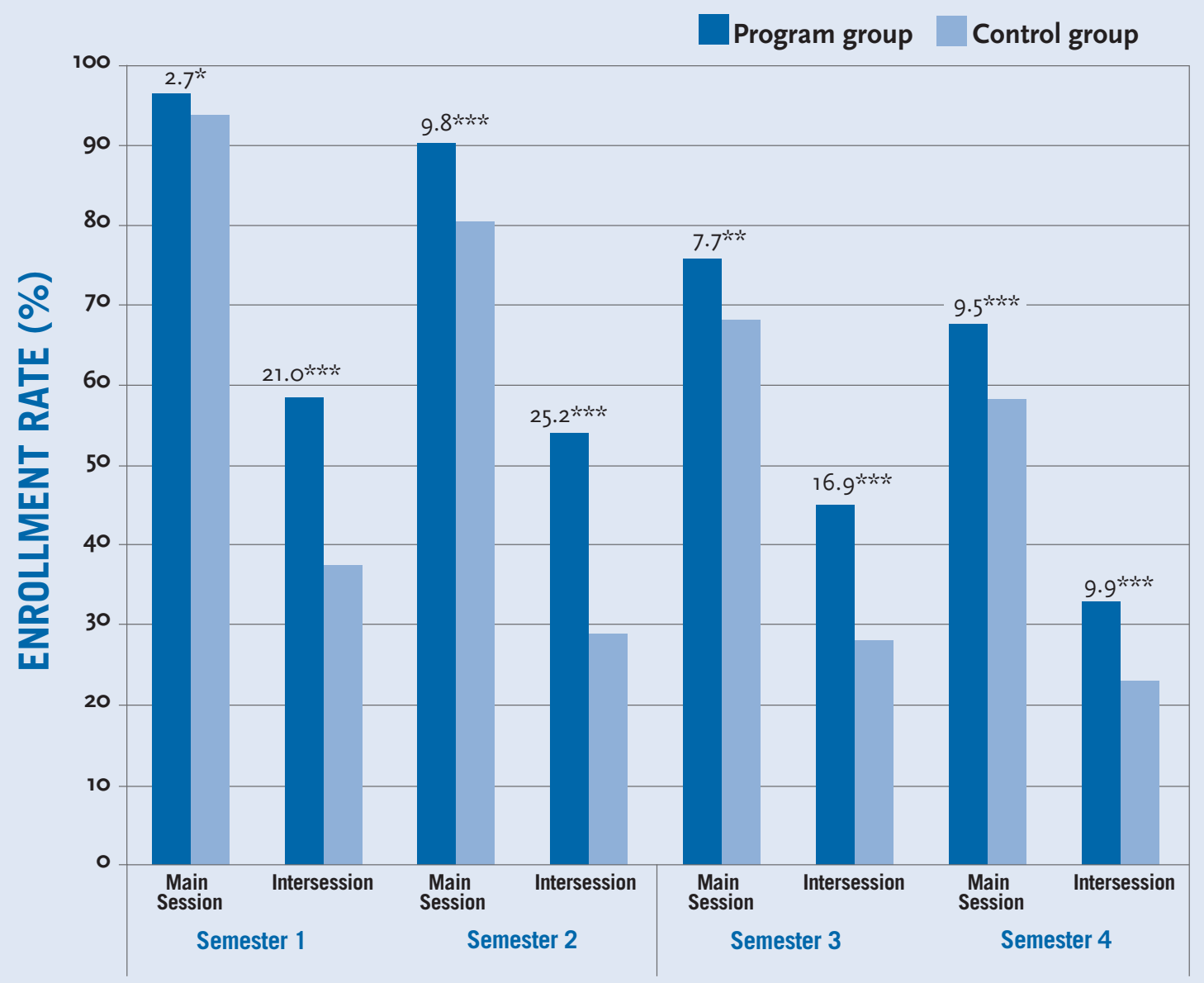

YEAR 1

YEAR 2

SOURCE: MDRC calculations from CUNY Institutional Research Database.

NOTES: A two-tailed t-test was applied to differences between research groups. Statistical significance levels are indicated as:

$* * * * 1$ percent; $* *=5$ percent; $*=10$ percent.

Estimates are adjusted by site and cohort.

Enrollment is based on courses in which students are still enrolled as of the end of the add/drop period.

\section{TIMING OF ACADEMIC SEMESTERS}

At Kingsborough Community College and LaGuardia Community College, the academic calendar includes a fall and a spring semester, with two sessions: a 12-week main session followed by a 6-week intersession. Borough of Manhattan Community College is more traditional, with a 16-week fall semester, a 3-week winter intersession, a 16-week spring semester, and two 6-week summer sessions. In this brief, Borough of Manhattan's fall and spring semesters are referred to as main sessions, and the winter and summer sessions as intersessions. of the second, third, and fourth semesters of the follow-up period, ASAP's estimated effects on enrollment rates were $9.8,7.7$, and 9.5 percentage points, respectively. Asterisks above the bars indicate that results are statistically significant. (See the box on page 7 for an explanation of the asterisks.)

During the first four intersessions, ASAP's estimated effects on enrollment were even larger: 21.0, 25.2, 16.9, and 9.9 percentage points, respectively. The larger estimated effects during the intersessions likely reflect three factors: (1) control group students enrolled at a low rate, leaving a greater margin for 
improvement; (2) the program requires fulltime enrollment (attempting 12 or more credits) and the intersession credits count toward full-time enrollment (at two of the three study colleges); and (3) ASAP advisers encouraged students to enroll during intersessions.

\section{ASAP Boosts Credit Accumulation}

Figure 2, on page 8 , presents cumulative total credits earned (both developmental and college-level) at any CUNY college during the first two years after students were randomly assigned. ASAP had a positive (and increasing) effect on cumulative credits earned during each of the eight sessions of follow-up. Early in the follow-up period (semester 1), ASAP's positive effect on total credit accumulation was fairly evenly split between developmental credits and college-level credits (not shown in figure). By the end of two years, over 80 percent of the effect on total credits was a result of college-level credits, as students progressed beyond their developmental requirements. After two years, students who were offered ASAP earned an average of 37.9 credits; their control group counterparts, an average of 30.4 credits. Thus, over two years ASAP is estimated to have increased credit accumulation by 7.6 credits. $^{12}$

How should the magnitude of this effect be interpreted? Program group students earned, on average, 25 percent more credits than their control group counterparts. Because most college courses are worth three or four credits, on average students in the program group completed two to three more courses than expected. Put another way, since most associate's degrees require students to earn 60 college-level credits (not including developmental education courses), 7.6 credits represents around 13 percent of the collegelevel credits required to earn a degree.

To put this effect in a broader context, the
WHAT DO THE ASTERISKS IN THE

EXHIBITS MEAN?

Once students are assigned to a program group or a control group, MDRC follows their outcomes and applies a two-tailed t-test to determine the statistical significance of the difference in outcomes between the research groups. The test is conducted to determine the probability that the observed difference (or a larger difference than the one observed) could have occurred by chance even if the program had no real effect. In the figures and table in this brief, the number of asterisks indicates the probability of observing the same or larger differences if the program had no real effect. In short, the more asterisks, the more confident one can be that the program had an effect. Statistical significance levels are indicated as: $* * * *=1$ percent; $* * * 5$ percent; $*=10$ percent.

estimated effect on two-year credit accumulation is the largest that MDRC has observed to date in over 15 random assignment evaluations of community college interventions. In fact, the next largest estimated effect on two-year credit accumulation is less than half the magnitude of ASAP's. Linking these findings back to the effect of ASAP on enrollment, around 30 percent of the effect on cumulative total credits earned occurred during intersessions.

\section{ASAP Increases Rates of Graduation}

As noted, the vast majority of study participants required developmental course work. In order to earn an associate's degree at CUNY two-year colleges, these students must therefore earn at least 60 college-level credits on top of any developmental credits they are required to earn. Consequently, graduating within two years (four semesters) requires an average course load of more than 15 credits per semester. This is an important context to keep in mind when viewing the two-year graduation results: though the colleges involved in this evaluation are often referred to as "two-year" colleges, graduating within this time frame is probably unrealistic for most students with developmental needs. In 


\section{FIGURE 2: ASAP INCREASES CREDITS EARNED OVER TWO YEARS}

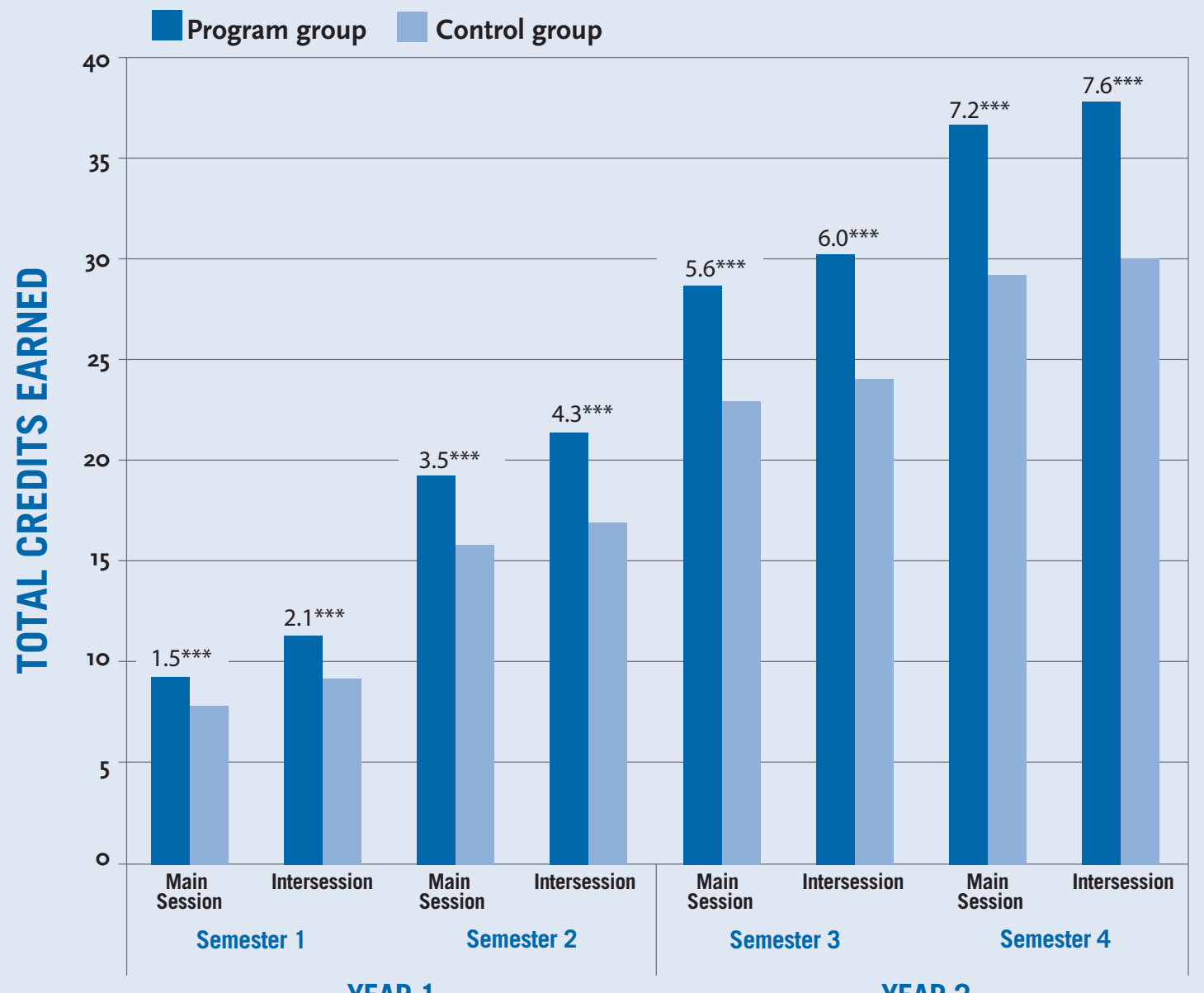

YEAR 1

YEAR 2

SOURCE: MDRC calculations from CUNY Institutional Research Database.

NOTES: A two-tailed t-test was applied to differences between research groups. Statistical significance levels are indicated as:

$* * * * 1$ percent; $* * *=5$ percent; $*=10$ percent.

Estimates are adjusted by site and cohort.

addition, because most ASAP services are provided for three years, program group students who are still enrolled after two years are eligible to receive services for another full year.

Table 1 presents estimates of the effects of ASAP on degree completion at any college (including schools outside the CUNY system) during the two years after students entered the evaluation. ${ }^{13}$ These findings indicate that ASAP had a positive and statistically significant effect on graduation rates. Specifically, two-year graduation rates were 8.7 percent for the control group and 14.5 percent for the program group; thus, ASAP is estimated to have increased graduation rates by 5.7 percentage points. As of two years, all degrees earned are associate's degrees.

\section{Looking Beyond Two Years}

Thus far ASAP's effects have been presented for the full MDRC study sample of 896 students using two years of follow-up data. For the first cohort of students, whose first semester in the study was spring 2010, an additional semester of follow-up is available. This cohort represents approximately one-third of the full sample $(\mathrm{N}=327)$ and includes students from two of the study's three colleges (Borough of Manhattan Community College and Kingsborough Community College). Results indicate that ASAP's effects on graduation rates for this cohort grow dramatically by the two-and- 


\section{TABLE 1: ASAP RAISES TWO-YEAR GRADUATION RATES}

a-half-year mark. At that point, 33.3 percent of program group members from the first cohort had earned an associate's degree, compared with 18.2 percent of control group members from that cohort, yielding an estimated impact of 15.1 percentage points. This finding should be taken with some caution in that it represents only one-third of the full ASAP sample. The result suggests, however, that ASAP's effect on graduation rates over two and a half years for the full sample will be much larger than its effects on two-year graduation rates. A future MDRC report will provide detailed findings for the full sample, including three-year graduation rates.

\section{CONCLUSION S}

\section{A N D LOOKING} F O R W A R D

Over a two-year follow-up period, ASAP had a dramatic effect on students' academic attainment. Compared with the colleges' usual services, ASAP substantially increased persistence, the average number of credits that students earned, and graduation rates. Most notably, the program increased the proportion of students who graduated within two years by almost 6 percentage points - a 66 percent increase over the control group's graduation rate.

ASAP's combination of a full-time enrollment requirement and a rich array of services and financial supports is helping students progress far beyond where they would have been had they received typical college services. To the authors' knowledge, ASAP's increases are larger than the effects of any other com-

\section{OUTCOME (\%)}

PROGRAM GROUP

CONTROL GROUP

EARNED A DEGREE FROM ANY COLLEGE ${ }^{a}$

\begin{tabular}{|c|c|c|c|}
\hline SEMESTER 1 & 0 & 0 & 0 \\
\hline SEMESTER 2 & 0.2 & 0 & 0.2 \\
\hline SEMESTER 3 & 2.9 & 1.1 & $1.7^{*}$ \\
\hline SEMESTER 4 & 14.5 & 8.7 & $5.7^{* * * *}$ \\
\hline
\end{tabular}

HIGHEST DEGREE EARNED

CERTIFICATE

ASSOCIATE'S DEGREE

BACHELOR'S DEGREE OR HIGHER

SAMPLE SIZE (TOTAL $=896)$

SOURCE: MDRC calculations from CUNY Institutional Research Database and National Student Clearinghouse data.

NOTES: Rounding may cause slight discrepancies in sums and differences.

levels are indicated as: $* * * ;=1$ percent; $* * ;=5$ percent; $*=10$ percent.

Estimates are adjusted by site and cohort.

The data in this table combine the BMCC fall and winter sessions into one semester and the

Degree receipt is cumulative: those who earned a degree in an earlier semester are counted as having a degree in subsequent semesters. munity college program that has been studied to date using a large-scale, rigorous experimental design. These findings provide some confirmation of a hypothesis suggested by earlier research: in order to substantially boost students' success, comprehensive, extended interventions may be needed.

Providing ASAP's multiple components for up to three years costs more than delivering standard college services. A study by the Center for Benefit-Cost Studies in Education at Teachers College, Columbia University, found that for the first group of students to participate in ASAP, who entered the program in 2007 and in many cases continued to take part in future years, the program was cost-effective, costing less per graduate than standard college services. ${ }^{14}$ MDRC is currently conducting a study comparing the cost of services for the program group and the control group. 
Based on results from their own internal study of early cohorts of students and the promising early effects from the random assignment evaluation, CUNY committed to substantially expanding ASAP beginning in fall 2012. By fall 2014, CUNY aims to serve over 4,000 students at the six participating community colleges - three times more than were served in fall 2012. On a different but related note, the ASAP model has proven successful enough to inform the development of CUNY's newest school, Guttman Community College, located in Manhattan. This institution, which opened its doors in 2012, provides a clearly defined first-year program for students that requires full-time attendance.

Given that ASAP's services and supports last three years, the very encouraging findings of this brief tell only part of the story. MDRC plans to publish a report in 2014 that shares ASAP's effects on three-year graduation rates and other academic outcomes. The report will also provide detailed findings from MDRC's study of the implementation and costs of ASAP.

As policymakers, college administrators, and philanthropists seek solutions to the nation's seemingly intractable completion problem in community colleges, the results presented in this brief suggest that ASAP is a model worthy of very serious consideration.

\section{NOTE S}

'Horn and Berger (2004).

${ }^{2}$ Bailey, Jeong, and Cho (2010).

${ }^{3}$ Berkner, He, and Cataldi (2002).

${ }^{4}$ Linderman and Kolenovic (2009).

5ASAP advisers' caseload sizes grew somewhat larger beginning in fall 2012, as ASAP began to serve more students. MDRC field research suggests that the advisement of the study's program group was not substantially affected.

${ }^{6}$ MetroCards, which are issued by New York City's Metropolitan Transit Authority, are used to access public transportation in New York City.

${ }^{7}$ Learning communities are groups of students who take two or more linked courses together that have mutually reinforcing themes and assignments. The learning communities seek to encourage peer relationships, intensify personal connections to faculty, and foster a deeper mastery of course work.

${ }^{8}$ When ASAP was launched in 2007, CUNY had six community colleges. The seventh, Guttman Community College, opened its doors in 2012.

${ }_{9}^{9}$ The excluded majors are allied health sciences, pre-clinical nursing, forensic science, and engineering science at Borough of Manhattan Community College; nursing at Kingsborough Community College; and allied health sciences and engineering science at LaGuardia Community College. The study also excluded undocumented immigrants because they are not eligible to receive federal financial aid or the ASAP tuition waiver.

${ }^{\circ}$ Based on data from CUNY's Institutional Research Database (IRDB), the main source for this brief, 39 percent of the sample members needed one developmental course when they entered the study and 51 percent needed two courses. Two percent of the students in the sample did not need any developmental courses, and 8 percent needed three or more. (These numbers differ somewhat from those presented in MDRC's first report from the study owing to newly available data and information about the colleges' developmental placement procedures.) One college implemented the eligibility criteria differently from the others and accepted students who needed multiple math courses even if it meant they needed more than two courses; that college accounts for the majority of students whom MDRC identified as needing three or more developmental courses at baseline (three-fourths of the 8 percent). Nearly all other students identified by MDRC as ineligible due to the number of courses needed at baseline were, in fact, eligible according to CUNY analysis using data sources other than the IRDB.

"The academic outcomes of program group members presented in this brief and other MDRC reports from the ASAP random assignment evaluation will not align exactly with the academic outcomes for ASAP students presented in reports from CUNY's internal evaluation of ASAP because the groups of students examined differ somewhat. First, MDRC's outcomes reflect the academic progress of all students who are part of the random assignment study. A small proportion of program group students ( 5 percent) did not enroll in college or ASAP by CUNY's official enrollment census date of their first semester in the study. These students are included in MDRC's analyses because they are critical for maintaining the integrity of the experiment. CUNY's evaluation, in contrast, only includes students who were enrolled in ASAP as of CUNY's official enrollment census date. Second, ASAP serves some undocumented immigrants. Because those students are not eligible for federal financial aid, they are not eligible for the ASAP tuition waiver. Inasmuch as MDRC's evaluation was designed to 
study the effects of the full package of ASAP services, undocumented immigrants were not included in the MDRC research sample. Those students are included in CUNY's analysis.

${ }^{12}$ Data are rounded to the nearest tenth.

${ }^{13}$ Includes any college covered by the National Student Clearinghouse, which provides information on enrollment and degree attainment at colleges across the nation.

${ }^{14}$ Levin and Garcia (2012).

\section{REFERENCES}

Bailey, Thomas, Dong Wook Jeong, and SungWoo Cho. 2010. "Referral, Enrollment, and Completion in Developmental Education Sequences in Community Colleges." Economics of Education Review 29: 255-270.

Berkner, Lutz, Shirley He, and Emily F. Cataldi. 2002. Descriptive Summary of 1995-96 Beginning

\section{A C K N O W L E D G M E N T S}

The City University of New York (CUNY) launched Accelerated Study in Associate Programs (ASAP) in 2007 with funding from New York City's Center for Economic Opportunity (CEO), and CEO has continued supporting the program. In 2009, senior university leadership from the CUNY Office of Academic Affairs - Alexandra Logue, Executive Vice Chancellor for Academic Affairs and University Provost; John Mogulescu, Senior University Dean for Academic Affairs and Dean of the School of Professional Studies; and David Crook, University Dean for Institutional Research and Assessment - approached MDRC about the possibility of evaluating ASAP, and we enthusiastically accepted the offer.

We are very grateful to Donna Linderman, the University Associate Dean for Student Success Initiatives and ASAP Executive Director, and to Zineta Kolenovic, ASAP Assistant Director for Research and Evaluation, for their assistance, support, and feedback. We also greatly appreciate the assistance and support of many administrators and staff at Borough of Manhattan Community College (BMCC), Kingsborough Community College (KCC), and LaGuardia Community College (LCCC), especially President Antonio Pérez and Senior Vice President for Academic Affairs Sadie Bragg at BMCC; former President Regina Peruggi and current Interim President Stuart Suss at KCC; and President Gail Mellow, former Vice President for Academic Affairs Peter Katopes, and Associate Dean for Academic Affairs Ann Feibel at LGCC. The colleges' ASAP directors - Lesley Leppert-McKeever at BMCC; Richard Rivera at KCC; and Bernard Pol-
Postsecondary Students: Six Years Later. Washington, D.C.: U.S. Department of Education, National Center for Education Statistics.

Horn, Laura, and Rachael Berger. 2004. College Persistence on the Rise? Changes in 5-Year Degree Completion and Postsecondary Persistence Rates Between 1994 and 2000. Washington, D.C.: U.S. Department of Education, National Center for Education Statistics.

Levin, Henry, and Emma Garcia. 2012. Cost-Effectiveness of Accelerated Study in Associate Programs (ASAP) of the City University of New York (CUNY). New York: Center for Benefit-Cost Studies in Education, Teachers College, Columbia University.

Linderman, Donna, and Zineta Kolenovic. 2009. Early Outcomes Report for City University of New York (CUNY) Accelerated Study in Associate Programs (ASAP). New York: The City University of New York. nariev, who is now Executive Associate to the Dean for Academic Affairs at LGCC; and current director Leslie Camacho - have been terrific partners in the study.

The ASAP evaluation is supported by the Leona M. and Harry B. Helmsley Charitable Trust and the Robin Hood Foundation.

Dissemination of MDRC publications is supported by the following funders that help finance MDRC's public policy outreach and expanding efforts to communicate the results and implications of our work to policymakers, practitioners, and others: The Annie E. Casey Foundation, The George Gund Foundation, Sandler Foundation, and The Starr Foundation.

In addition, earnings from the MDRC Endowment help sustain our dissemination efforts. Contributors to the MDRC Endowment include Alcoa Foundation, The Ambrose Monell Foundation, Anheuser-Busch Foundation, Bristol-Myers Squibb Foundation, Charles Stewart Mott Foundation, Ford Foundation, The George Gund Foundation, The Grable Foundation, The Lizabeth and Frank Newman Charitable Foundation, The New York Times Company Foundation, Jan Nicholson, Paul H. O'Neill Charitable Foundation, John S. Reed, Sandler Foundation, and The Stupski Family Fund, as well as other individual contributors.

The findings and conclusions in this report do not necessarily represent the official positions or policies of the funders. 


\section{More Graduates}

Two-Year Results from an Evaluation of Accelerated Study in Associate Programs (ASAP) for Developmental Education Students

By Susan Scrivener and Michael J. Weiss

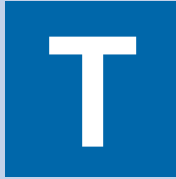

his policy brief presents results from a random assignment evaluation of the City University of New York's Accelerated Study in Associate Programs (ASAP). An ambitious and promising endeavor, ASAP provides a comprehensive array of services and supports to help community college students graduate and to help them graduate sooner. The evaluation targeted low-income students who needed one or two developmental (remedial) courses. ASAP requires students to enroll full time and provides block-scheduled classes, comprehensive advisement, tutoring, career services, a tuition waiver, free monthly MetroCards for use on public transportation, and free use of textbooks for up to three years. After two years, compared with regular college services, ASAP increased the number of credits students earned as well as their persistence in college. Most notably, the program boosted twoyear graduation rates substantially — by 66 percent. A future report will present the program's effects after three years. 